\title{
Novel transient-energy-based directional pilot protection method for HVDC line
}

\author{
Guibin Zou ${ }^{1 *}$ (D), Qiang Huang ${ }^{1}$, Shenglan Song ${ }^{2}$, Bingbing Tong ${ }^{3}$ and Houlei Gao ${ }^{1}$
}

\begin{abstract}
This paper proposes a novel directional pilot protection method based on the transient energy for bipolar HVDC line. Supposing the positive direction of current is from DC bus to the DC line, in the case of an internal line fault, the transient energies detected on both sides of the line are all negative within a short time, which denotes the positive direction fault; while for an external fault, the transient energy on one end is positive, which means a negative direction fault, but the transient energy on the opposite end is negative, which indicates that the fault direction is positive. According to these characteristics, an integration criterion identifying fault direction is constructed. In addition, through setting a fixed energy threshold, the faulted line and lightning disturbance can also be discriminated. Simulation results from UHVDC transmission system show the validity of the proposed protection method.
\end{abstract}

Keywords: Transient energy, HVDC line, Directional pilot protection, Fault direction, Lightning stroke

\section{Introduction}

Compared with the high voltage AC power transmission, HVDC power transmission has some advantages, such as larger transmission capacity, longer transmission distance, lower line loss, etc., which is becoming an important power transmission way on asynchronous grid interconnection and clean energy power integration [1-3]. Because of the long distance and passing through the valleys and mountains, HVDC lines easily suffer from the faults caused by lightning, storm, and so on. Therefore, to ensure the safety and stability of DC transmission system, a fast, reliable and sensitive HVDC line protection is indispensable.

At present, the primary protections used in HVDC line are traveling wave protection and voltage variation protection, which have poor ability to resist the high ground resistance fault [4]. Additionally, their performances are also affected by other disturbance signals. HVDC line differential protection used for the back-up protection also has certaion shortcomings, such as slow operation speed and requiring the synchronous data $[5,6]$.

\footnotetext{
* Correspondence: guibinzou@sdu.edu.cn

${ }^{1}$ Key Laboratory of Power System Intelligent Dispatch and Control of Ministry of Education, Shandong University, Ji'nan, China

Full list of author information is available at the end of the article
}

Aiming at these problems mentioned above, many protection methods have been put forward. In [7], authors analyze the performances of HVDC line protection for different fault transition resistance, fault position, etc., and finally present several improvement suggestions. Through analyzing the harmonic current characteristics of converter station, a protection scheme based on the transient harmonic current is present for HVDC line in [8]. According to the boundary characteristics of HVDC line, some protection methods only using one-end information are proposed in [9-12]. Although these methods have fast speed, their sensitivity and reliability are still influenced by the fault resistance, in addition, it is also difficult to set the threshold value. In $[13,14]$, authors propose the distance protection methods for HVDC line, but the high ground resistance fault still has a negative influence on their protection performances. To improve the reliability of protection, the hybrid protection schemes based on different principles are put forward in [15-17], but implementing these schemes is still a challenge in actual HVDC transmission engineering.

In [18] and [19], the transient-energy based protection methods are proposed for HVDC line, which can identify an internal or external fault by comparing the amplitudes of the transient energies on both ends of the line, these 
methods are similar to the current differential protection, and they need strict data synchronization. Different from the aforementioned methods, this paper presents a novel directional pilot protection method based on the polarity characteristic of transient energy. For a fault inside the DC line, the transient energies detected on both sides of HVDC line are negative; while the transient energy on one side is positive, and that on the other side is negative for an external fault. On the basis of this fact, an integral criterion identifying the fault direction is constructed. By analyzing the fault directions on both sides, the internal fault can be discriminated from the external fault. Due to only using the directional information, the proposed protection method does not require the synchronous data at all. To verify the performance of the proposed method, a bipolar HVDC transmission system model is built, and extensive simulations are carried out.

\section{Methods}

2.1 Characteristic analysis of transient energy

\subsubsection{Simplified equivalent circuit of HVDC transmission}

\section{system}

To simply analyze, the converter may be approximate equivalent to a series of voltage source and impedance, this equivalent circuit does not produce an obvious influence on the fault analysis. Figure 1 shows the equivalent circuit of single-pole HVDC system, where $Z_{e q}$ denotes the equivalent impedance of the converter station; $Z_{L}$ is the impedance of DC line; $u_{m+}$ and $i_{m+}$ are the voltage and current at terminal $\mathrm{M}$, respectively; $u_{n+}$ and $i_{n+}$ are the voltage and current at terminal $\mathrm{N}$, respectively; $u_{1}$ and $u_{2}$ are the equivalent voltage sources at two converters. Here, supposing the positive direction of current is from DC bus to DC line, as shown in Fig. 1. The main fault types for bipolar DC line include the single pole to earth faults and pole to pole fault, where the single pole to earth faults contain the positive pole to earth fault and the negative pole to earth fault. The analyses of internal and external faults for HVDC line are described as below.



Fig. 1 Simplified equivalent circuit of DC power transmission system

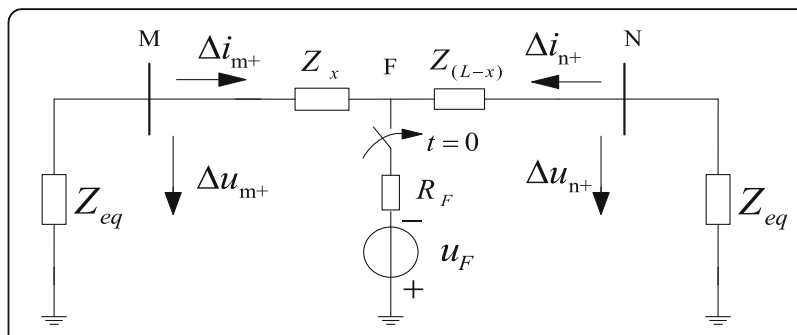

Fig. 2 Fault superimposed circuit for a positive-pole to earth fault

\subsubsection{Transient energy characteristics for pole-earth fault}

If a pole-earth fault occurs on the positive pole line, Fig. 2 shows an equivalent fault superimposed circuit.

In Fig. 2, $L$ denotes the length of DC line; $\mathrm{F}$ is the fault point; $Z_{x}$ is the line impedance from $\mathrm{F}$ to terminal $\mathrm{M}$, and $Z_{(L-x)}$ is the line impedance from $\mathrm{F}$ to terminal $\mathrm{N} ; R_{\mathrm{F}}$ is the fault resistance; $u_{\mathrm{F}}$ represents the fault superimposed voltage source; $\Delta u_{\mathrm{m}+}$ and $\Delta i_{\mathrm{m}+}$ are the fault components of voltage and current at terminal $\mathrm{M}$, respectively; $\Delta u_{\mathrm{n}+}$ and $\Delta i_{\mathrm{n}+}$ are the fault components of voltage and current at terminal $\mathrm{N}$.

According to Fig. 2, the following equations can be obtained:

$$
\begin{aligned}
& \Delta u_{\mathrm{m}+}=-Z_{e q} \Delta i_{\mathrm{m}+} \\
& \Delta u_{\mathrm{n}+}=-Z_{e q} \Delta i_{\mathrm{n}+}
\end{aligned}
$$

From (1) and (2) it can be seen that the polarities of $\Delta u_{\mathrm{m}}$ + and $\Delta i_{\mathrm{m}+}$ are opposite, so are the polarities of $\Delta u_{\mathrm{n}+}$ and $\Delta i_{\mathrm{n}+}$. Therefore, the variations of transient power on both sides of the line $\Delta P_{\mathrm{m}_{+}}=\Delta u_{\mathrm{m}+} \Delta i_{\mathrm{m}+}$ and $\Delta P_{\mathrm{n}_{+}}=\Delta u_{\mathrm{n}+} \Delta i_{\mathrm{n}+}$ are all negative, further their integral values shown in (3) and (4) are also negative.

$$
\begin{aligned}
& S_{\mathrm{m}+}=\int_{0}^{\tau} \Delta P_{\mathrm{m}+}(t) d t \\
& S_{\mathrm{n}+}=\int_{0}^{\tau} \Delta P_{\mathrm{n}+}(t) d t
\end{aligned}
$$

where, $S_{\mathrm{m}+}$ and $S_{\mathrm{n}+}$ denote the transient energies measured at terminals $\mathrm{M}$ and $\mathrm{N}$ of the positive pole line, respectively; $\tau$ is the integral time. Here, the reason that introduces the transient power integral is to decrease the influence from disturbance and improve the reliability of protection.

Similarly, if there is a pole-earth fault occurring on the negative pole line, the transient energies $S_{\mathrm{m}-}$ and $S_{\mathrm{n}}$ detected at terminals $\mathrm{M}$ and $\mathrm{N}$ of the negative pole line are also negative.

\subsubsection{Transient energy characteristics for pole-pole fault}

If a bipolar line fault occurs on the HVDC lines, the fault superimposed circuit is shown in Fig. 3, where $F_{1}$ 


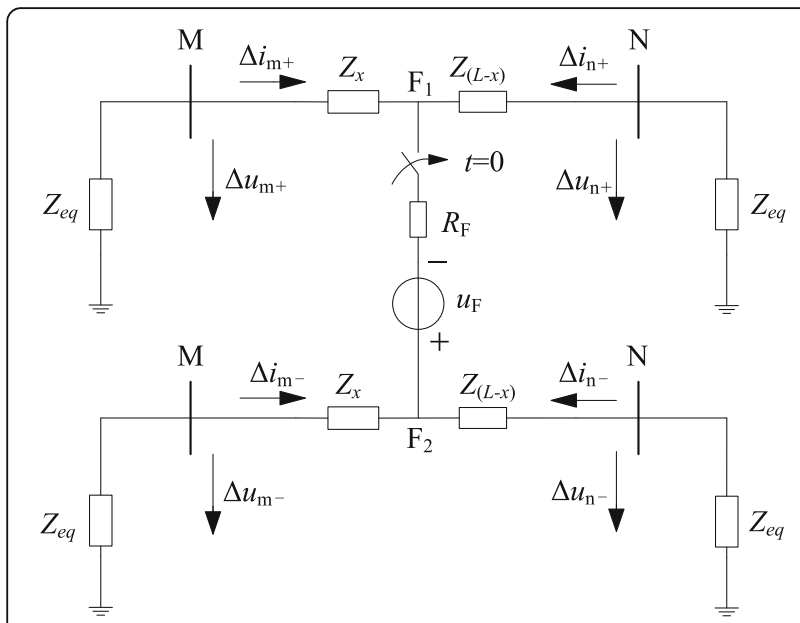

Fig. 3 Fault superimposed circuit for a pole-pole fault

and $F_{2}$ are the fault points on the positive pole line and negative pole line, respectively. $\Delta u_{\mathrm{m}-}$ and $\Delta i_{\mathrm{m} \text { - }}$ are the fault components of voltage and current at terminal $\mathrm{M}$ of the negative pole line; $\Delta u_{\mathrm{n}}$ - and $\Delta i_{\mathrm{n}}$ - are the fault components of voltage and current at terminal $\mathrm{N}$.

According to Fig. 3, the following equations can be obtained:

$$
\left\{\begin{array}{c}
\Delta u_{\mathrm{m}+}=-Z_{e q} \Delta i_{\mathrm{m}+} \\
\Delta u_{\mathrm{n}+}=-Z_{e q} \Delta i_{\mathrm{n}+} \\
\Delta u_{\mathrm{m}-}=-Z_{e q} \Delta i_{\mathrm{m}-} \\
\Delta u_{\mathrm{n}-}=-Z_{e q} \Delta i_{\mathrm{n}-}
\end{array}\right.
$$

From (5) it can be seen that the variations of transient power on each side of bipolar line are all negative and, after the integral calculation, the transient energies are also negative.

Based on the above analyses, the following conclusions can be drawn: for an internal DC line fault, whatever it is a single pole to earth fault or a pole to pole fault, the power variations on both sides of the faulted line are always negative, as well as the transient energies.

\subsubsection{Transient energy characteristics for external fault}

For HVDC line, external faults include two types, one type occurs on the DC side, and the other type occurs on the AC side. Actually, the influence generated by an AC side external fault on HVDC line protection is similar to that generated by a DC side external fault, and the transient analyses for the external faults are discussed as follows.

2.1.4.1 Faults outside the positive pole line If a fault occurs on the converter valve or DC bus of the rectifier side, the fault superimposed circuit is shown in Fig. 4a, where $Z_{e q 1}$ and $Z_{e q 2}$ are the equivalent impedances from


Fig. 4 Fault superimposed circuit for a fault occurring on the rectifier side. a Fault occurring on the converter valve or DC bus. b Fault occurring on the $A C$ side

the fault point to both sides of the rectifier station. For a fault occurring on the $\mathrm{AC}$ side at the rectifier station, the fault superimposed circuit is shown in Fig. 4b.

From Fig. $4, \Delta u_{\mathrm{m}+}$ and $\Delta i_{\mathrm{m}+}$ can be expressed as:

$$
\begin{aligned}
& \Delta u_{\mathrm{m}+}=\left(Z_{e q}+Z_{L}\right) \Delta i_{\mathrm{m}+} \\
& \Delta u_{\mathrm{n}+}=-Z_{e q} \Delta i_{\mathrm{n}+}
\end{aligned}
$$

In (6) and (7), the polarities of $\Delta u_{\mathrm{m}+}$ and $\Delta i_{\mathrm{m}+}$ at the rectifier side are the same, while those of $\Delta u_{\mathrm{n}+}$ and $\Delta i_{\mathrm{n}+}$ at the inverter side are opposite. Therefore, the transient power variation $\Delta P_{\mathrm{m}+}$ is positive, but $\Delta P_{\mathrm{n}+}$ is negative and, thus the transient energy $S_{\mathrm{m}+}$ is positive while $S_{\mathrm{n}+}$ is negative.

When a fault occurs on the converter valve or DC bus of the inverter side, the corresponding fault superimposed circuit is shown in Fig. 5a and b illustrates the fault superimposed circuit for a fault occurring on the AC side.

As shown in Fig. 5:

$$
\begin{aligned}
& \Delta u_{\mathrm{m}+}=-Z_{e q} \Delta i_{\mathrm{m}+} \\
& \Delta u_{\mathrm{n}+}=\left(Z_{e q}+Z_{L}\right) \Delta i_{\mathrm{n}+}
\end{aligned}
$$

From (8) and (9) it can be seen that the polarities of $\Delta u_{\mathrm{m}+}$ and $\Delta i_{\mathrm{m}+}$ at the rectifier side are opposite, while those of $\Delta u_{\mathrm{n}+}$ and $\Delta i_{\mathrm{n}+}$ at the inverter side are the same. Therefore, the transient power variation $\Delta P_{\mathrm{m}+}$ is negative, and $\Delta P_{\mathrm{n}+}$ is positive, so the corresponding transient energy $S_{\mathrm{m}+}$ is negative while $S_{\mathrm{n}+}$ is positive. 


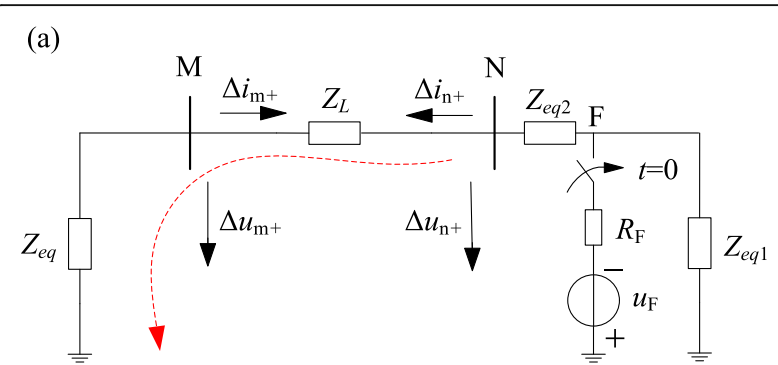

(b)



Fig. 5 Fault superimposed circuit for a fault occurring on the inverter side. a Fault occurring on the converter valve or DC bus. b Fault occurring on the AC side

2.1.4.2 Faults outside the negative pole line Similarly, the same conclusions as the aforementioned cases can be drawn: for the faults outside the negative pole line, no matter a fault occurs on the rectifier station or on the inverter station, the polarities of the transient energies detected on both sides of the negative pole line are always opposite.

\subsection{Protection criterion for HVDC line}

According to the analyses in Section 2.1, the following conclusions can be obtained: in case of an internal fault occurring on the HVDC line, the transient energies detected on both the rectifier side and the inverter side are all negative; but for a fault occurring outside the HVDC line, the transient energy on one side is positive, and the transient energy on the other side is negative.

Therefore, using the characteristic difference of transient energy after the fault, the fault direction can be determined. If the transient energy is negative, the fault direction is positive; if the transient energy is positive, the fault direction is negative. As a result, if the fault directions on both sides of HVDC line are all positive, an internal fault will be discriminated. However, If the fault direction on one side is positive, and that on the opposite side is negative, an external fault will be identified.

It has been specified that the substitution of transient energy for fault component power is to improve the reliability of protection.

To implement conveniently, the discretized transient energy equation of (3) and (4) can be expressed:

$$
S_{\eta p}=\Delta t \sum_{1}^{j} \Delta u_{\eta p}(k) \Delta i_{\eta p}(k)
$$

where, $\Delta u_{\eta p}(k)$ and $\Delta i_{\eta p}(k)$ are the fault components of voltage and current at the $k$ th sampling point, which can be extracted by filtering load component; $j$ is the number of the sampling point used for integral calculation; $\Delta t$ is the sampling interval; $\eta$ denotes the rectifier side $\mathrm{M}$ or the inverter side $\mathrm{N}$; the variable $p$ denotes + or -, which means the positive pole line or the negative pole line. In actual calculation process, $\Delta t$ may be omitted.

If a single pole to earth fault occurs, the transient signals on the faulted line can be coupled to the normal line, which possibly affects the fault identification of the normal line. Moreover, lightning stroke or normal operation can also generate disturbance signals. To avoid these influences, a fixed energy threshold $S_{\text {set }}$ is necessary, which is defined as follows:

$$
S_{\text {set }}=j k_{r e l} k_{i} k_{u}
$$

where $k_{r e l}$ is the reliable coefficient; $k_{i}$ and $k_{u}$ are the proportional coefficients of rated current and rated voltage, respectively. Note that the rated current and the rated voltage are all expressed as per unit value here, so that $S_{\text {set }}$ can be applied to different HVDC system. In addition, for a long HVDC line, the probability of lightning stroke is high. Therefore, lightning stroke line

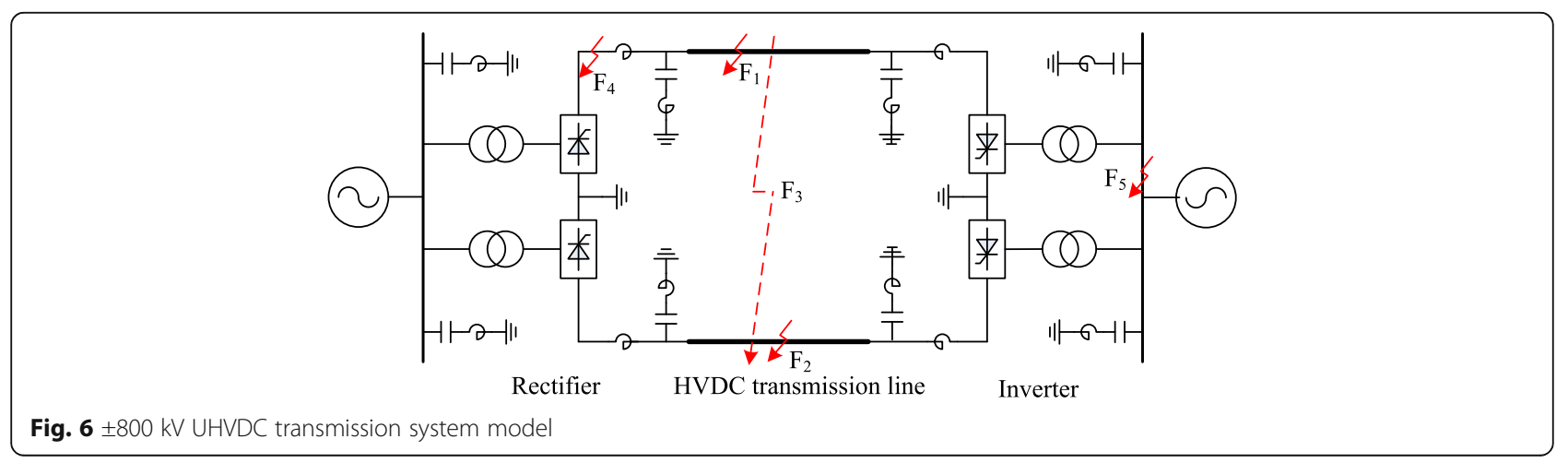


without causing fault must be correctly identified by the protection. The sampling frequency of the proposed method is relatively low $(10 \mathrm{kHz})$ and integral calculation is used in the algorithm, which can filter high frequency components to some extent. Moreover, the amplitude of lightning current for direct stroke line is low $[20,21]$, and generally the transient energy caused by lightning disturbance will not exceed the fixed threshold.

For convenient analysis, a rule is defined here. The logic value of a positive directional fault is 1 , and that of the negative directional fault is equal to -1 , and 0 means there is no fault. Therefore, the transient energy direction $\operatorname{Dir}\left[S_{\eta p}\right]$ is expressed as follows:

$$
\operatorname{Dir}\left[S_{\eta p}\right]=\left\{\begin{aligned}
-1 & S_{\eta p} \geq S_{\text {set }} \\
0 & \left|S_{\eta p}\right|<S_{\text {set }} \\
1 & S_{\eta p} \leq-S_{\text {set }}
\end{aligned}\right.
$$

The logic identifying fault is described as below: if the logic values of fault direction detected on both sides of HVDC line are equal to 1 , an internal fault will be determined; if the logic value of fault direction on one side is 1 , while that on the other side is -1 , an external fault will be discriminated; otherwise, it is normal.

\section{Results and discussion}

\subsection{Simulation and analysis}

\subsubsection{Simulation model}

To test the performance of the proposed protection principle, using the actual parameters of $\pm 800 \mathrm{kV}$ HamiZhengzhou HVDC transmission system in China, this paper constructs a simulation model of bipolar UHVDC system with a double 12-pulse valves at each converter


Fig. 7 Waveforms of fault components and transient energies detected on the positive pole line for a fault at $F_{1}$. a Rectifier station. b Inverter station
Table 1 Simulation results for a fault at $F_{1}$

\begin{tabular}{llllllllll}
\hline Location & $R_{\mathrm{F}}(\Omega)$ & Pole & \multicolumn{2}{c}{ Rectifier side } & & \multicolumn{2}{l}{ Inverter side } & Result \\
& & & $S_{\mathrm{m}}$ & Dir & & $S_{\mathrm{n}}$ & Dir & \\
\hline $\mathrm{F}_{1}$ & 300 & + & -1.96 & 1 & & -1.91 & 1 & Internal \\
& & - & $/$ & $/$ & & $/$ & $/$ & Normal
\end{tabular}

station. The frequency-dependent line model is utilized for accurate simulation. As shown in Fig. 6, the length of UHVDC line is $2190 \mathrm{~km}$, the transmission capacity is up to $8000 \mathrm{MW}$, and the rated current is $5 \mathrm{kA}$.

In Fig. 6, extensive internal and external faults will be simulated, and the sampling frequency is $10 \mathrm{kHz}$. Practical operating experience shows the polarity of lightning current is generally negative, so the lightning stroke mainly occurs on the positive pole line and a standard 2.6/50 $\mu$ s lightning current is used in the simulation. A multi-wave-impedance tower model, a flashover insulator model and a nonlinear surge earth impedance model are included to evaluate the back-flashover accurately. For convenient analysis, the fault components of voltage and current, and the value of transient energy are all expressed in per unit value. Considering the lightning stroke interference of $2 \sim 3 \mathrm{~ms}$ and the influence of fault resistance, the integral time is set as $5 \mathrm{~ms}$, and the fixed threshold $S_{\text {set }}$ is set as 1 here.

\subsubsection{Typical internal faults}

3.1.2.1 Single-pole to earth fault When a fault occurs on the positive pole line at $F_{1} 500 \mathrm{~km}$ from the rectifier station, and the fault ground resistance and fault initial instant are $300 \Omega$ and $0 \mathrm{~ms}$, respectively. The waveforms of fault component voltage and fault component current,
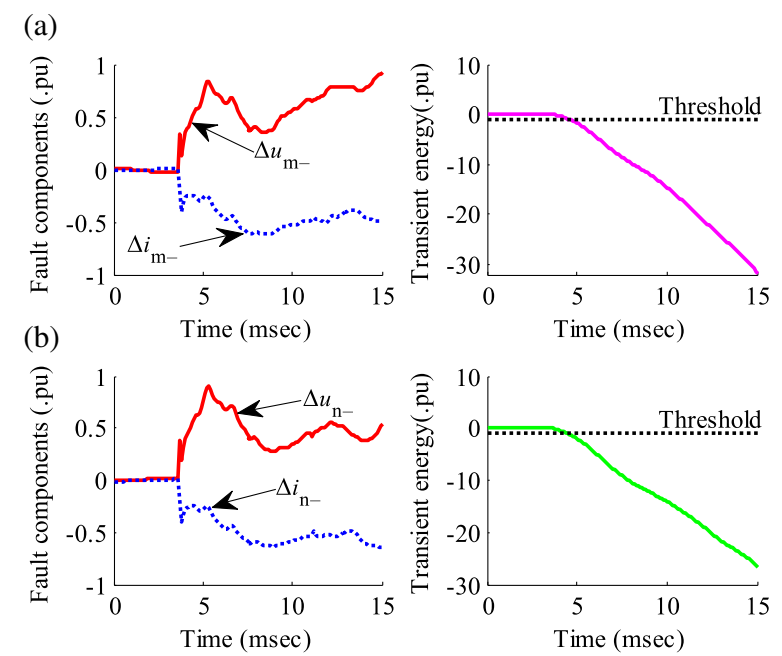

Fig. 8 Waveforms of fault components and transient energies detected on the negative pole line for a fault at $F_{2}$ a Rectifier station. b Inverter station 


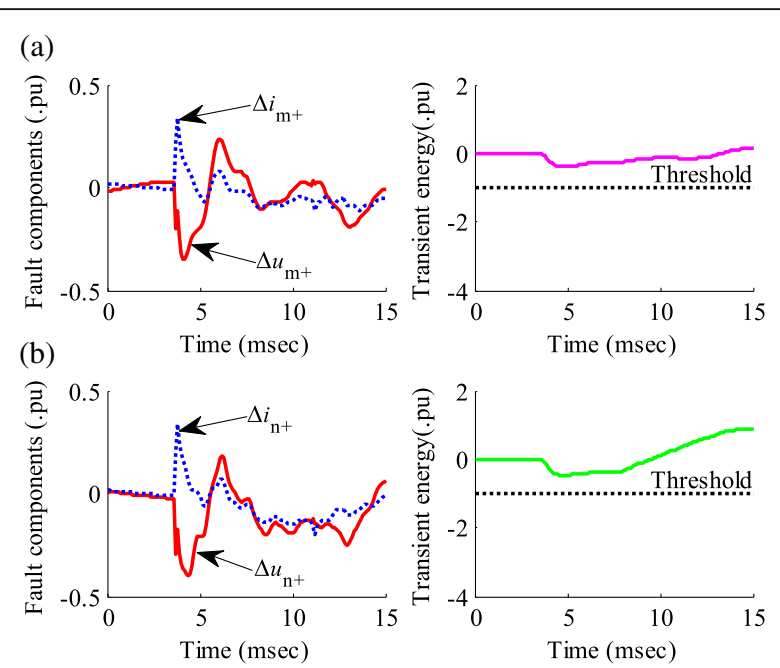

Fig. 9 Waveforms of fault components and transient energies detected on the positive pole line for a fault at $F_{2}$ a Rectifier station. b Inverter station

and the waveforms of transient energies detected on the rectifier side and the inverter side are shown in Figs. 7a and $b$, respectively. The corresponding simulation results are listed in Table 1, where $R_{F}$ denotes the fault ground resistance, sign/means that the relay does not start. Here, once the variation of voltage exceeds 0.2 times rated voltage or the variation of current exceeds 0.1 times rated current in three consecutive samples, the relay starts.

For positive pole line, it can be seen from Fig. 7 and Table 1 that the polarities of fault component voltage and current are opposite; the transient energies detected on both the rectifier side and the inverter side are negative, and they all exceed the threshold value, so two protection units on both sides of the positive pole line identify a positive direction fault. According to the identification logic, finally an internal fault occurring on the positive pole line is verified. Therefore, the result is correct, and this method has a powerful ability to resist the fault resistance.

3.1.2.2 Metallic earth fault at $F_{2}$ For a fault at $F_{2}$ occurring on the middle of the negative pole line, Fig. 8 shows the waveforms of fault components and transient energies detected on both ends of the negative pole line, and the waveforms of fault components and transient energies detected on both ends of the positive pole line

Table 2 Simulation results for a fault at $F_{2}$

\begin{tabular}{llllllllll}
\hline Location & $R_{\mathrm{F}}(\Omega)$ & Pole & \multicolumn{2}{c}{ Rectifier side } & & \multicolumn{2}{l}{ Inverter side } & Result \\
& & & $S_{\mathrm{m}}$ & Dir & & $S_{\mathrm{n}}$ & Dir & \\
\hline $\mathrm{F}_{2}$ & 0 & + & -0.19 & 0 & & -0.19 & 0 & Normal \\
& & - & -11.01 & 1 & & -11.52 & 1 & Internal \\
\hline
\end{tabular}
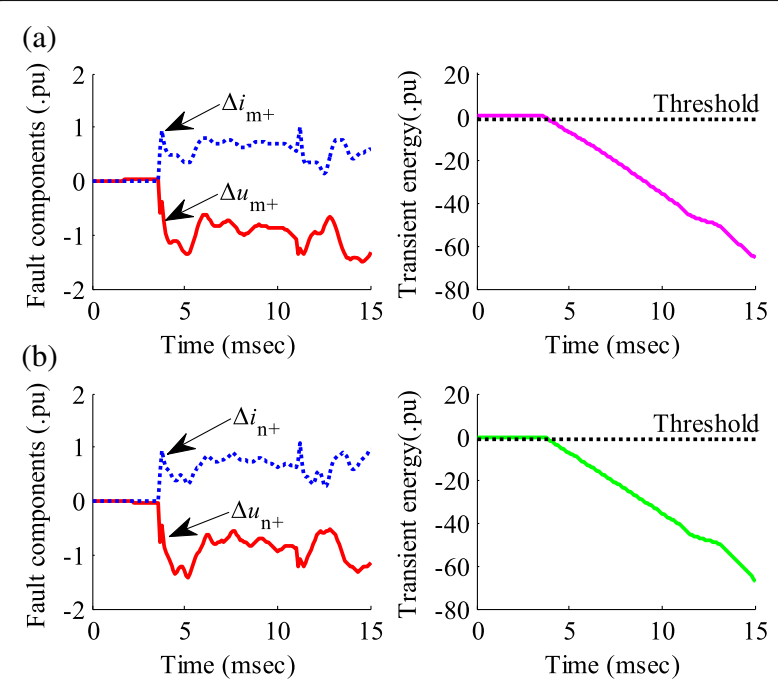

Fig. 10 Waveforms of fault components and transient energies detected on the positive pole line for a fault at $F_{3}$. a Rectifier station. b Inverter station

(normal line) are shown in Fig. 9. Table 2 shows the relevant simulation results.

From Fig. 8 and Table 2, it can be seen that the transient energies on both ends of the negative pole line have the same negative polarity and they both exceed the fixed threshold. Therefore, the protection units at two sides of the negative pole line identify a positive direction fault, finally an internal fault occurring on the negative pole line is determined.

Because of the coupling influence, the transient voltage and current can also be detected on the normal line. As shown in Fig. 9 and Table 2, the transient voltage
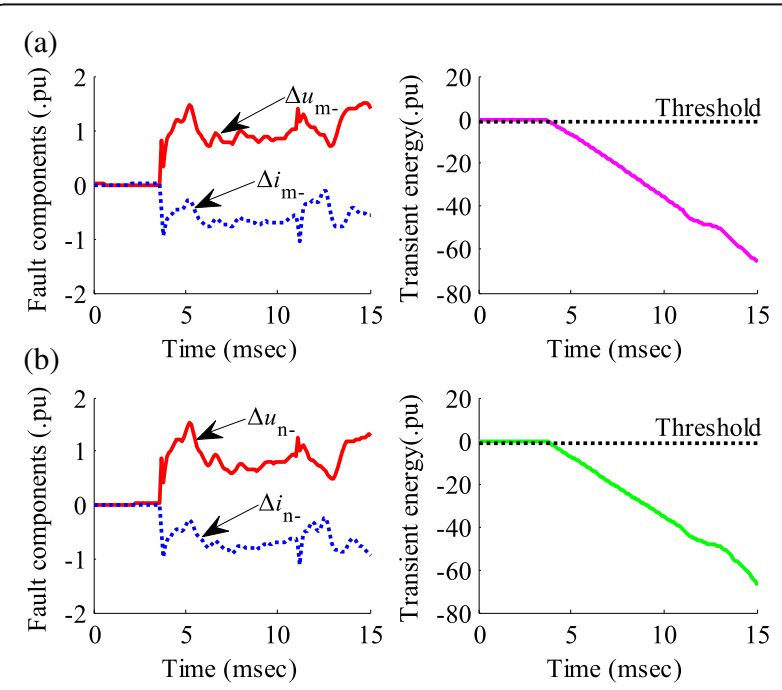

Fig. 11 Waveforms of fault components and transient energies detected on the negative pole line for a fault at $F_{3}$. a Rectifier station. $\mathbf{b}$ Inverter station 
Table 3 Simulation results for a fault at $F_{3}$

\begin{tabular}{|c|c|c|c|c|c|c|c|}
\hline \multirow[t]{2}{*}{ Location } & \multirow[t]{2}{*}{$\mathrm{R}_{\mathrm{F}}(\Omega)$} & \multirow[t]{2}{*}{ Pole } & \multicolumn{2}{|c|}{ Rectifier side } & \multicolumn{2}{|c|}{ Inverter side } & \multirow[t]{2}{*}{ Result } \\
\hline & & & $S_{m}$ & Dir & $S_{n}$ & Dir & \\
\hline \multirow[t]{2}{*}{$\mathrm{F}_{3}$} & 0 & + & -27.41 & 1 & -27.66 & 1 & Internal \\
\hline & & - & -27.63 & 1 & -27.72 & 1 & Internal \\
\hline
\end{tabular}

and current on two ends of the positive pole line rise at fault initial stage for a fault at $F_{2}$, but the transient energies detected on both ends of the line don't exceed the fixed threshold, thus the protection units at two ends will not operate. Therefore, through setting a fixed threshold, a single pole to earth fault has no effect on the fault identification of the normal line.

3.1.2.3 Pole to pole fault at $F_{3}$ For a pole to pole fault at $F_{3}$ occurring on the middle of the bipolar line, Figs. 10 and 11 show the transient waveforms detected on both ends of the bipolar line, and the simulation data are shown in Table 3.

As shown in Figs. 10, 11 and Table 3, the transient energies detected on the positive pole line and the negative pole line exceed the fixed threshold, so the protection units at two ends of the bipolar line all identify a positive direction fault. In combination with the results on the two sides, a fault inside both the positive pole line and the negative pole line is identified, and the results are correct.

\subsubsection{Typical external faults}

3.1.3.1 External fault at $\mathbf{F}_{\mathbf{4}}$ Supposing a fault occurs at $\mathrm{F}_{4}$ on the DC bus of the positive pole line in the rectifier station, Fig. 12 shows the transient waveforms detected

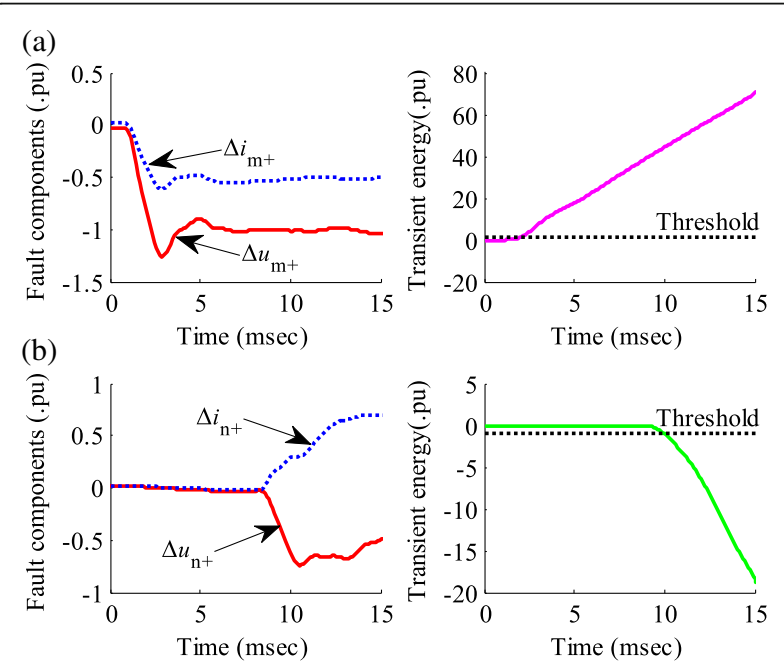

Fig. 12 Waveforms of fault components and transient energies detected on the positive pole line for a fault at $\mathrm{F}_{4}$. a Rectifier station. b Inverter station
Table 4 Simulation results for a fault at $\mathrm{F}_{4}$

\begin{tabular}{|c|c|c|c|c|c|c|c|}
\hline \multirow[t]{2}{*}{ Location } & \multirow[t]{2}{*}{$R_{F}(\Omega)$} & \multirow[t]{2}{*}{ Pole } & \multicolumn{2}{|c|}{ Rectifier side } & \multicolumn{2}{|c|}{ Inverter side } & \multirow[t]{2}{*}{ Result } \\
\hline & & & $S_{m}$ & Dir & $S_{n}$ & Dir & \\
\hline \multirow[t]{2}{*}{$\mathrm{F}_{4}$} & 0 & + & 23.73 & -1 & -14.01 & 1 & External \\
\hline & & - & 1.85 & -1 & -4.05 & 1 & External \\
\hline
\end{tabular}

on the positive pole line, and the simulation results are indicated in Table 4.

From Fig. 12 and Table 4, it can be seen that the transient energies detected on both ends of the positive pole line have obvious differences. The transient energy detected on the rectifier side is positive while it is negative on the inverter side. According to the fault identification logic, the protection unit at the rectifier side identifies a negative direction fault while the protection unit at the inverter side identifies a positive direction fault. Through analyzing the above results, an external fault is finally determined, and the same characteristic exists in the negative pole line, so the identification results are all correct.

3.1.3.2 External fault at $F_{5}$ For a fault at $F_{5}$ occurring on the AC side of the inverter station, Figs. 13 and 14 illustrate the transient waveforms detected on the positive pole line and the negative pole line, respectively, and Table 5 lists the relevant simulation results.

As shown in Figs. 13, 14, and Table 5, the polarities of transient energies detected on both ends of the positive line and the negative line are all opposite. Therefore, an external fault will be identified and the discrimination results are correct.

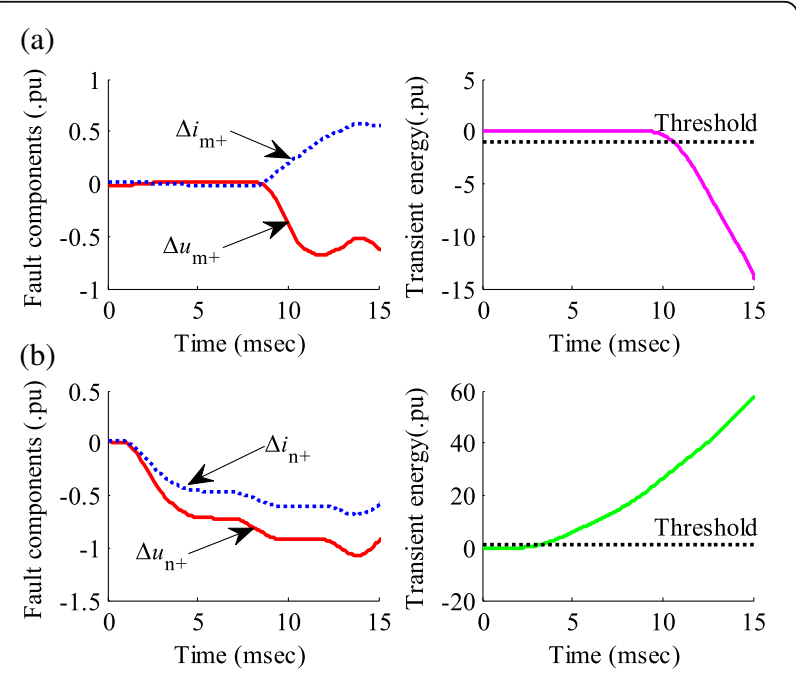

Fig. 13 Waveforms of fault components and transient energies detected on the positive pole line for a fault at $F_{5}$ a Rectifier station. b Inverter station 


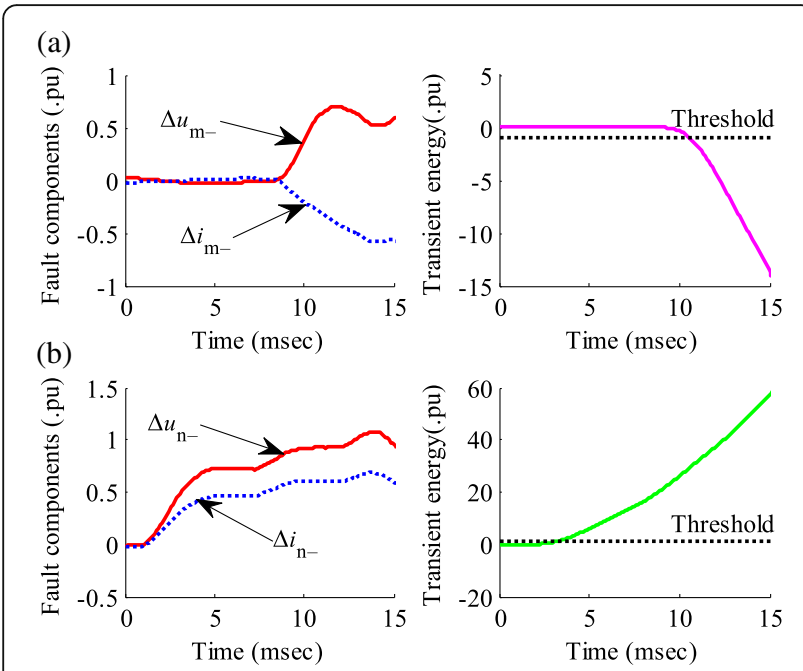

Fig. 14 Waveforms of fault components and transient energies detected on the negative pole line for a fault at $F_{5}$. a Rectifier station. $\mathbf{b}$ Inverter station

\subsubsection{Simulation analysis of the influence factors}

3.1.4.1 Fault location and fault ground resistance Both the fault location and the fault ground resistance have certain impacts on the traditional DC line protection. To verify whether these factors have influences or not on the proposed protection method, the following simulations are carried out. Several faults with different fault ground resistances at different locations are set, and the simulation results for internal faults and external faults are shown in Tables 6 and 7, respectively.

As seen from Table 6, for the single pole to earth faults or the pole-pole faults with different fault locations and different fault ground resistances, although the fault resistance has a negative influence on the transient energy value, the proposed method can still identify these faults, and the results are all correct.

For external faults with different fault ground resistances, the simulation results from Table 7 show that the proposed protection method can accurately identify these external faults, and the results are all right.

3.1.4.2 Lightning stroke As mentioned in Section 2, lightning stroke on line or tower without causing fault may result in the maloperation of protective relay, so it is necessary to study the influence of lightning stroke on the proposed method. Tables 8 and 9 show the

Table 5 Simulation results for a fault at $F_{5}$

\begin{tabular}{|c|c|c|c|c|c|c|c|}
\hline \multirow[t]{2}{*}{ Location } & \multirow[t]{2}{*}{$\mathrm{R}_{\mathrm{F}}(\Omega)$} & \multirow[t]{2}{*}{ Pole } & \multicolumn{2}{|c|}{ Rectifier side } & \multicolumn{2}{|c|}{ Inverter side } & \multirow[t]{2}{*}{ Result } \\
\hline & & & $S_{m}$ & Dir & $S_{n}$ & Dir & \\
\hline \multirow[t]{2}{*}{$\overline{F_{5}}$} & 0 & + & -11.08 & 1 & 12.24 & -1 & External \\
\hline & & - & -11.20 & 1 & 12.48 & -1 & External \\
\hline
\end{tabular}

Table 6 Simulation results for internal DC line faults

\begin{tabular}{|c|c|c|c|c|c|c|c|}
\hline \multirow[t]{2}{*}{ Location } & \multirow[t]{2}{*}{$\mathrm{R}_{\mathrm{F}}(\Omega)$} & \multirow[t]{2}{*}{ Pole } & \multicolumn{2}{|c|}{ Rectifier station } & \multicolumn{2}{|c|}{ Inverter station } & \multirow[t]{2}{*}{ Result } \\
\hline & & & $S_{m}$ & Dir & $S_{n}$ & Dir & \\
\hline \multirow[t]{6}{*}{$\mathrm{F}_{1}(1 \mathrm{~km})$} & 10 & + & -34.02 & 1 & -10.51 & 1 & Internal \\
\hline & & - & -0.27 & 0 & -2.44 & 1 & Normal \\
\hline & 200 & + & -5.64 & 1 & -1.91 & 1 & Internal \\
\hline & & - & / & / & -0.43 & 0 & Normal \\
\hline & 300 & + & -3.24 & 1 & -1.13 & 1 & Internal \\
\hline & & - & / & / & / & / & Normal \\
\hline \multirow[t]{6}{*}{$F_{2}(500 \mathrm{~km})$} & 10 & + & -0.17 & 0 & -0.64 & 0 & Normal \\
\hline & & - & -13.23 & 1 & -9.33 & 1 & Internal \\
\hline & 200 & + & / & / & -0.04 & 0 & Normal \\
\hline & & - & -2.85 & 1 & -2.37 & 1 & Intern \\
\hline & 300 & + & / & / & / & / & Normal \\
\hline & & - & -1.70 & 1 & -1.71 & 1 & Internä \\
\hline \multirow[t]{6}{*}{$\mathrm{F}_{3}(1000 \mathrm{~km})$} & 10 & + & -24.96 & 1 & -25.01 & 1 & Internal \\
\hline & & - & -25.21 & 1 & -25.09 & 1 & Internal \\
\hline & 200 & + & -8.13 & 1 & -8.44 & 1 & Internal \\
\hline & & - & -8.20 & 1 & -8.46 & 1 & Internal \\
\hline & 300 & + & -5.37 & 1 & -5.69 & 1 & Interna \\
\hline & & - & -5.40 & 1 & -5.80 & 1 & Interna \\
\hline
\end{tabular}

simulation results for lightning stroke disturbance and lightning stroke causing fault, respectively. It has to been explained, for direct lightning stroke, that only the positive pole line is considered.

From Table 8 it can be seen, for lightning stroke without causing fault, that no matter it strikes on line or tower, the identification results are all correct. Moreover, for lightning

Table 7 Simulation results for faults outside the DC line

\begin{tabular}{|c|c|c|c|c|c|c|c|}
\hline \multirow[t]{2}{*}{ Location } & \multirow[t]{2}{*}{$\mathrm{R}_{\mathrm{F}}(\Omega)$} & \multirow[t]{2}{*}{ Pole } & \multicolumn{2}{|c|}{ Rectifier station } & \multicolumn{2}{|c|}{ Inverter station } & \multirow[t]{2}{*}{ Result } \\
\hline & & & $S_{m}$ & Dir & $S_{n}$ & Dir & \\
\hline \multirow[t]{6}{*}{$\overline{F_{4}}$} & 10 & + & 19.14 & -1 & -11.08 & 1 & $\overline{\text { External }}$ \\
\hline & & - & 1.61 & -1 & -3.16 & 1 & External \\
\hline & 200 & + & 1.66 & -1 & -0.88 & 0 & Normal \\
\hline & & - & / & / & -0.14 & 0 & Normal \\
\hline & 300 & + & 0.83 & 0 & -0.26 & 0 & Normal \\
\hline & & - & / & / & / & / & Normal \\
\hline \multirow[t]{4}{*}{$F_{5}(A G)$} & 10 & + & -2.70 & 1 & 2.94 & -1 & External \\
\hline & & - & -2.74 & 1 & 3.02 & -1 & External \\
\hline & 300 & + & / & / & / & / & Normal \\
\hline & & - & / & / & / & / & Normal \\
\hline \multirow[t]{4}{*}{$\mathrm{F}_{5}(\mathrm{BCG})$} & 10 & + & -11.92 & 1 & 12.10 & -1 & External \\
\hline & & - & -11.50 & 1 & 12.22 & -1 & External \\
\hline & 300 & + & / & / & / & / & Normal \\
\hline & & - & / & / & / & / & Normal \\
\hline
\end{tabular}


Table $\mathbf{8}$ Simulation results for lightning stroke disturbance

\begin{tabular}{|c|c|c|c|c|c|c|}
\hline \multicolumn{3}{|l|}{ Condition } & \multirow{2}{*}{$\begin{array}{l}\text { Pole } \\
+\end{array}$} & \multirow{2}{*}{$\frac{S_{m}}{0.29}$} & \multirow{2}{*}{$\begin{array}{l}S_{n} \\
0.04\end{array}$} & \multirow{2}{*}{$\frac{\text { Result }}{\text { Normal }}$} \\
\hline Lightning stroke on line without causing fault & $20 \mathrm{kA}$ & $100 \mathrm{~km}$ & & & & \\
\hline & & & - & 0.10 & 0.02 & Normal \\
\hline & & 1095 km & + & -0.01 & -0.01 & Normal \\
\hline & & & - & 0.03 & / & Normal \\
\hline & $30 \mathrm{kA}$ & $10 \mathrm{~km}$ & + & 1.95 & -0.05 & Normal \\
\hline & & & - & -0.13 & 0.05 & Normal \\
\hline & & $1500 \mathrm{~km}$ & + & 0.17 & 0.15 & Normal \\
\hline & & & - & 0.07 & 0.13 & Normal \\
\hline \multirow[t]{8}{*}{ Lightning stroke on tower without causing back-flashover } & $50 \mathrm{kA}$ & $1 \mathrm{~km}$ & + & I & / & Normal \\
\hline & & & - & / & / & Normal \\
\hline & & $2100 \mathrm{~km}$ & + & / & / & Normal \\
\hline & & & - & / & / & Normal \\
\hline & $100 \mathrm{kA}$ & $10 \mathrm{~km}$ & + & / & / & Normal \\
\hline & & & - & / & / & Normal \\
\hline & & $1800 \mathrm{~km}$ & + & / & / & Normal \\
\hline & & & - & / & / & Normal \\
\hline
\end{tabular}

stroke on tower without causing back-flashover, the protection units will not start.

As shown in Table 9, for shielding failure and backflashover with different lightning current amplitudes and lightning stroke locations, those faults can also be correctly identified. Note that lightning stroke on tower with the amplitude of $200 \mathrm{kA}$ causes both the positive pole and negative pole insulators back-flashover, but for lightning current of $120 \mathrm{kA}$, it only results in the insulator back-flashover of positive pole line. Therefore, the

Table 9 Simulation results for lightning stroke causing faults

\begin{tabular}{|c|c|c|c|c|c|c|}
\hline \multicolumn{3}{|l|}{ Condition } & \multirow{2}{*}{$\begin{array}{l}\text { Pole } \\
+\end{array}$} & \multirow{2}{*}{$\frac{S_{m}}{-29.83}$} & \multirow{2}{*}{$\frac{S_{\mathrm{n}}}{-9.14}$} & \multirow{2}{*}{$\frac{\text { Result }}{\text { Internal }}$} \\
\hline Shielding failure & $15 \mathrm{kA}$ & $1 \mathrm{~km}$ & & & & \\
\hline & & & - & -0.23 & -2.13 & Normal \\
\hline & & 500 km & + & -12.33 & -8.77 & Internal \\
\hline & & & - & -0.10 & -0.62 & Normal \\
\hline & $30 \mathrm{kA}$ & 300 km & + & -13.79 & -8.48 & Internal \\
\hline & & & - & 0.15 & -0.84 & Normal \\
\hline & & 900 km & + & -10.84 & -9.18 & Internal \\
\hline & & & - & -0.14 & -0.27 & Normal \\
\hline \multirow[t]{8}{*}{ Back- flashover } & $120 \mathrm{kA}$ & 10 km & + & -38.95 & -11.56 & Internal \\
\hline & & & - & -0.34 & -2.40 & Normal \\
\hline & & 1200 km & + & -9.46 & -12.06 & Internal \\
\hline & & & - & -0.57 & 0.88 & Normal \\
\hline & $200 \mathrm{kA}$ & 1095 km & + & -28.07 & -27.16 & Internal \\
\hline & & & - & -26.86 & -28.61 & Internal \\
\hline & & 2100 km & + & -25.49 & -33.10 & Internal \\
\hline & & & - & -25.23 & -28.75 & Internal \\
\hline
\end{tabular}

protection criteria can effectively discriminate between lightning stroke disturbance and lightning stroke fault.

\section{Conclusions}

Using the characteristic differences of transient energy on both sides of HVDC line after the fault, the paper proposes a novel directional pilot protection method. From the theoretical analysis and simulation results, the following conclusions can be obtained:

1) Due to applying directional pilot protection principle and energy integral criteria, the proposed protection method is rarely influenced by fault position, fault resistance and lightning stroke disturbance. For special fault cases, such as close-up faults or high ground resistance faults, the method can make a correct identification, so it has absolute selectivity and high reliability.

2) The proposed protection criteria can correctly identify the faulted line for a single pole to earth fault, so the method has good adaptability.

3) Because of only identifying the fault directions on both sides of HVDC line, so the pilot protection does not require the synchronous data.

\section{Acknowledgements}

This work was supported in part by National Natural Science Foundation of China (51677109), and in part by National Key Research and Development Program of China (2016YFB0906003).

\section{Authors' contributions}

Guibin Zou carried out the protection principle studies, drafted the manuscript. Qiang Huang participated in the sequence alignment. Shenglan Song and Bingbing Tong carried out the simulation and analysis. Houlei Gao participated in protection principle study and the design of study. All authors read and approved the final manuscript. 


\section{Competing interests}

The authors declare that they have no competing interests.

\section{Author details}

'Key Laboratory of Power System Intelligent Dispatch and Control of Ministry of Education, Shandong University, Ji'nan, China. ${ }^{2}$ State Grid Weifang Electric Power Company, Weifang 261021, China. ${ }^{3}$ State Grid Langfang Electric Power Company, Langfang 065000, China.

Received: 1 December 2016 Accepted: 21 March 2017

Published online: 20 April 2017

\section{References}

1. Yang, J., Fletcher, J. E., \& O'Reilly, J. (2010). Multiterminal dc wind farm collection grid internal fault analysis and protection design. IEEE Transactions on Power Delivery, 25(4), 2308-2318.

2. Bresesti, P., Kling, W. L., Hendriks, R. L., et al. (2007). HVDC connection of offshore wind farms to the transmission system. IEEE Transactions on Energy Conversion, 22(1), 37-43.

3. Andersen, B. R., \& Lie, X. (2004). Hybrid HVDC system for power transmission to island networks. IEEE Transactions on Power Delivery, 19(4), 1884-1890.

4. Zhang, S., \& Li, Y. L. (2011). Simulation and analysis of HVDC line protection under the single pole to ground fault with high transition resistance (Electric Utility Deregulation and Restructuring and Power Technologies, 2011 4th International Conference on, pp. 926-929).

5. Li, A. M., Cai, Z. X., Sun, Q. Z., et al. (2009). Study on the dynamic performance characterisitcs of HVDC control and protections for the HVDC line fault (Power \& Energy Society General Meeting, p. 5).

6. Gao, S. P., Chu, X., Shen, Q. Y., et al. (2015). A novel whole-line quick-action protection principle for HVDC transmission lines using one-end voltage. International Journal of Electrical Power and Energy Systems, 65, 262-270.

7. Kong, F., Hao, Z. G., Zhang, S., et al. (2014). Development of a novel protection device for bipolar HVDC transmission lines. IEEE Transactions on Power Delivery, 29(5), 2270-2278.

8. Song, G. B., Chu, X., Gao, S. P., et al. (2015). A new whole-line quick-action protection principle for HVDC transmission lines using one-end current. IEEE Transactions on Power Delivery, 30(2), 599-607.

9. Liu, K. Z., Yu, J. L., Shu, H. C., et al. (2012). Study on electrical transient protection for $\pm 800 \mathrm{kV}$ UHVDC Transmission Lines. In:sia-Pacific Power and Energy Engineering Conference.

10. Takeda, H., Ayakawa, H., Tsumenaga, M., et al. (2012). New protection method for HVDC lines including cables. IEEE Transactions on Power Delivery, 10(4), 2035-2039.

11. Ha, H., Yu, Y., \& Yi, R. (2010). Novel scheme of traveling wave based differential protection for bipolar HVDC transmission lines (Proceedings of the International Conference Power Systems, Technology, p. 5).

12. Zheng, X. D., Tai, T. N. L., Thorp, J. S., et al. (2001). A Transient Harmonic Current Protection Scheme for HVDC Transmission Line. IEEE Transactions on Power Delivery, 27(4), 2278-2285.

13. Han, K. L., Cai, Z. X., Liu, Y., et al. (2011). Study on protective performance of HVDC transmission line protection with different types of line fault (Electric utility deregulation and restructuring and power technologies (DRPT), pp. 358-361)

14. Li, A. M., Cai, Z. X., Sun, Q. Z., et al. (2009). Study on the dynamic performance characteristics of HVDC control and protections for the HVDC line fault (Power \& energy society general meeting, p. 5)

15. Zheng, X. D., Tai, N. L., Yang, G. L., et al. (2012). A transient protection scheme for HVDC transmission line. IEEE Transactions on Power Delivery, 27(2), 718-724.

16. Liu, X. L., Osman, A. H., \& Malik, O. P. (2009). Hybrid traveling wave/boundary protection for monopolar HVDC line. IEEE Transactions on Power Delivery, 24(2), 569-578.

17. Kerf, K. D., Srivastava, K., Reza, M., et al. (2012). Wavelet-based protection strategy for DC faults in multi-terminal VSC HVDC system. IET Generation Transmission and Distribution, 5(4), 496-503.

18. Liu, X. L., Osman, A. H., \& Malik, O. P. (2011). Real-time implementation of a hybrid protection scheme for double-pole HVDC line using FPGA. IEEE Transactions on Power Delivery, 26(1), 101-108.

19. Liang, Y. S., Wang, G., \& Li, H. F. (2015). Time-Domain Fault-Location Method on HVDC Transmission Lines Under Unsynchronized Two-End Measurement and Uncertain Line Parameters. IEEE Transactions on Power Delivery, 30(3), 1031-1038.
20. Azizi, S., Sanaye-Pasand, M., Abedini, M., et al. (2014). A Traveling-WaveBased Methodology for Wide-Area Fault Location in Multiterminal DC Systems. IEEE Transactions on Power Delivery, 29(6), 2552-2560.

21. Nanayakkara, O. M. K. K., Rajapakse, A. D., \& Wachal, R. (2012). TravelingWave-Based Line Fault Location in Star-Connected Multiterminal HVDC Systems. IEEE Transactions on Power Delivery, 27(4), 2286-2294.

\section{Submit your manuscript to a SpringerOpen ${ }^{\circ}$ journal and benefit from:}

- Convenient online submission

- Rigorous peer review

- Immediate publication on acceptance

- Open access: articles freely available online

- High visibility within the field

- Retaining the copyright to your article

Submit your next manuscript at springeropen.com 